\title{
Consensus on the Statin of Choice in Patients with Impaired Glucose Metabolism: Results of the DIANA Study
}

\author{
Jesús Millán Núñez-Cortés ${ }^{1,9}$ - Aleix Cases Amenós ${ }^{2}$ Juan Francisco Ascaso Gimilio ${ }^{3}$. \\ Vivencio Barrios Alonso ${ }^{4}$. Vicente Pascual Fuster ${ }^{5} \cdot$ Juan Carles Pedro-Botet Montoya $^{6}$. \\ Xavier Pintó Sala ${ }^{7}$ Adalberto Serrano Cumplido ${ }^{8}$
}

Published online: 11 November 2016

(C) The Author(s) 2016. This article is published with open access at Springerlink.com

\begin{abstract}
Introduction and Objectives Despite the recognized clinical benefit of statins on cardiovascular prevention, providing correct management of hypercholesterolaemia, possible adverse effects of their use cannot be disregarded. Previously published data shows that there is a risk of developing diabetes mellitus or experiencing changes in glucose metabolism in statin-treated patients. The possible determining factors are the drug characteristics (potency, dose), patient characteristics (kidney function, age,
\end{abstract}

Jesús Millán Núñez-Cortés

jesus.millan@salud.madrid.org

1 Internal Medicine Department, Hospital General

Universitario Gregorio Marañón, School of Medicine of the

Universidad Complutense, Madrid, Spain

2 Nephrology Department, Hospital Clínic de Barcelona, Barcelona, Spain

3 Endocrinology and Nutrition Department, Hospital Clínico Universitario, Universitat de Valencia, Valencia, Spain

4 Cardiology Department, Hospital Universitario Ramón y Cajal, Universidad de Alcalá, Madrid, Spain

5 Centro de Salud Palleter, Castellón, Spain

6 Unit of Lipids and Vascular Risk, Hospital del Mar, Universitat Autònoma de Barcelona, Barcelona, Spain

7 Unit of Lipids and Vascular Risk, Hospital Universitario de Bellvitge, L'Hospitalet de Llobregat, Barcelona, Spain

8 Centro de Salud de Repélega, Repélega, Portugalete, Vizcaya, Spain

9 Cátedra-Servicio de Medicina Interna, Hospital General Universitario Gregorio Marañón, Facultad de Medicina de la Universidad Complutense, Calle del Dr. Esquerdo, 46, 28007 Madrid, Spain cardiovascular risk and polypharmacy because of multiple disorders) and the pre-diabetic state.

Methods In order to ascertain the opinion of the experts (primary care physicians and other specialists with experience in the management of this type of patient) we conducted a Delphi study to evaluate the consensus rate on diverse aspects related to the diabetogenicity of different statins, and the factors that influence their choice.

Results Consensus was highly significant concerning aspects such as the varying diabetogenicity profiles of different statins, as some of them do not significantly worsen glucose metabolism. There was an almost unanimous consensus that pitavastatin is the safest statin in this regard.

Conclusions Factors to consider in the choice of a statin regarding its diabetogenicity are the dose and patient-related factors: age, cardiovascular risk, diabetes risk and baseline metabolic parameters (which must be monitored during the treatment), as well as kidney function.

Keywords Statins - Diabetes - Impaired glucose tolerance Consensus

\section{Key Points}

To minimize the risk of metabolic changes related to prediabetes or diabetes it is important to select the statin treatment in accordance with the patients and drugs characteristics

All statins do not exert a similar influence on glucose metabolism 


\section{Introduction}

The introduction of HMG-CoA reductase inhibitors in the treatment of dyslipidaemia, specially statins as cholesterollowering drugs, has been one of the biggest milestones in the recent history of cardiovascular events prevention, and there are numerous interventional studies that have demonstrated their clinical benefits in different scenarios of cardiovascular prevention [1,2].

In patients with diabetes, the benefit of statins is also significant, and can be greater than that found in high-risk non-diabetic patients [3]. The 4S, CARE, LIPID, and HPS studies have demonstrated decreased cardiovascular events and total mortality in patients with Type 2 Diabetes Mellitus (DM2) treated with statins [4-7]. In the analysis of diabetic patients in the ASCOT-LLA study [8], a reduced risk of cardiovascular accidents was also observed with atorvastatin, though it was not significant. However, in another study in diabetics (CARDS) [9], it was possible to demonstrate a clear and significant reduction in cardiovascular accidents with atorvastatin, even in patients with low levels of low-density lipoprotein cholesterol (LDL-C).

However, treatment with statins is not devoid of possible unwanted side effects [10]. These effects usually depend on different factors such as the type and dose of the statin used the patient's characteristics (age, kidney function, etc.) and the possible interactions with other drugs in patients who, due to multiple illnesses or comorbidity, are prescribed multiple medications. One of the adverse effects described has been the effect on glucose metabolism, modifying the levels of fasting glucose and glycosylated haemoglobin, and an increase in the onset of new cases of diabetes [11, 12]. Despite these effects, and as a result of the beneficial effect of statins in cardiovascular medicine, the European Medicines Agency (EMA) acknowledged the superiority of the potential benefits against the possible onset of new cases of diabetes [13]. However, the diabetogenic effect of statins may have been underestimated thus far, as most data has been collected from short-term clinical trials of up to 5 years [14], whereas the risk of onset of diabetes can remain increased for at least 20 years since the start of treatment [15].

The evidence collected from different meta-analyses indicates that statins may increase the risk of type 2 diabetes mellitus $[16,17]$. The most significant meta-analysis [17] has indicated that statin therapy is associated with a $9 \%$ increase in the risk of new cases of type 2 diabetes mellitus over 4 years, and that this risk is higher in older patients. However, this percentage can be increased in a striking way. In a study [18] involving 17,802 subjects treated with rosuvastatin in primary prevention, it was observed that the absolute risk of type 2 diabetes mellitus could be increased by up to $28 \%$ after 5 years of treatment; especially in patients with pre-diabetes: subjects with metabolic syndrome, impaired fasting glucose, obesity (BMI $\geq 30 \mathrm{~kg} / \mathrm{m}^{2}$ ), or with glycosylated haemoglobin (HbA1c) $>6 \%$. In a review of more than 15,000 patients [19], it was shown that the components of the metabolic syndrome were predictors of the onset of type 2 diabetes mellitus in statin-treated patients.

With regard to specific conditions of statins, a metaanalysis of five clinical trials involving about 33,000 nondiabetic patients showed that intensive treatment with high doses of statins may increase the risk of new cases of diabetes by $12 \%$ as compared to low doses [20]. Recent data from a retrospective study of actual clinical practice with more than 470,000 non-diabetic patients over 66 years of age treated with statins over a period of 14 years also showed a diabetogenic effect of statins associated with high (atorvastatin and rosuvastatin) or moderate (simvastatin) potency statins, with a 22 and $11 \%$ higher risk of onset of new diabetes, respectively [21]. Another population study, involving about 137,000 patients older than 40 years of age, confirmed that the risk of developing type 2 diabetes mellitus is $15 \%$ higher with high potency statins than low potency statins since 2 years after the start of treatment [22].

Summarizing, it is necessary to include diabetogenicity as one of the considerations in clinical practice when prescribing a treatment with statins. It appears to be a class effect although there may be differences based on the type of statin, the dose, its potency, as well as the patient profile (pre-diabetic condition or older age). Thus, in order to achieve the improvement in cardiovascular risk attributable to the statin, without increasing the risk of inducing alterations in glucose metabolism or generating diabetes, we should select the most favourable statin according to the patient profile.

This study has been proposed in order to ascertain the degree of consensus among physicians with wide experience in the management of patients requiring treatment with statins, about the factors that contribute to drug selection when there is impaired glucose metabolism. In particular, the objectives were to receive feedback on whether all statins have a similar or different diabetogenic effect and to establish recommendations on the statin selection based on the patient characteristics. The results shown are part of the DIANA study (DelphI study: multidisciplinary consensus on the stAtiN of choice in patients with Altered glucose metabolism). 


\section{Methods}

\subsection{Study Design}

The modified Delphi method [23] was used to reach the greatest consensus possible from a broad panel of dyslipidaemia experts. It is a structured technique for remote consensus, a variant of the original procedure developed by Dalkey et al. at Rand Corporation Santa Monica (California, United States) [24, 25], which maintains its key advantages (controlled interaction, opportunity to reconsider an opinion and statistical validation of consensus) over other technical alternatives and it addresses some of their major drawbacks (opinion biases) [26].

Its execution required two successive waves of a structured survey filled out through an online platform. The doctors were able to confidentially compare their personal opinions with the overall opinion of the panel when answering the second wave and could reconsider, where appropriate, their initial criteria on issues where there was no consensus.

The study was conducted in four phases: (a) the selection of a scientific committee, responsible for the formulation of the survey questions; (b) the selection of an expert panel of professionals from four specialties (cardiology, endocrinology, internal medicine, nephrology) and family and community medicine with experience in the field of dyslipidaemia; (c) an online survey in two waves; and (d) an analysis of results and discussion of conclusions in a meeting held by the scientific committee.

The project was performed over 5 months between February and June 2015 (wave 1 and wave 2, successively), using the email as the distribution channel.

\subsection{Preparation of the Questionnaire}

The project's scientific committee revised the contents of the Delphi questionnaire. A bibliographic search prioritising systematic reviews was conducted as well as another critical synthesis of scientific literature through the consultation of bibliographic databases (MEDLINE, EMBASE and the Spanish Medical Index) [27], and a manual review of the references obtained to find other references that may be of interest by using keywords such as dyslipidaemia, diabetogenicity or impaired glucose metabolism.

Each survey question submitted to the panel for assessment was devised in the form of a positive or negative statement, as a clinical recommendation responding to interesting or controversial aspects in the clinical management of patients with dyslipidaemia and impaired glucose metabolism. The final version of the questionnaire, included in this article, contained 2 blocks of questions: (1) Opinion on the profile of statins in the treatment of dyslipidaemia in patients with impaired glucose metabolism (16 questions), and (2) Recommendations for the selection of the lipid-lowering treatment of choice in patients with impaired glucose metabolism (24 questions).

\subsection{Selection of a Panel of Experts}

The experts proposed were selected by the committee based on their medical and scientific expertise and considering their interest in dyslipidaemia. For their recruitment, a "snowball" strategy was used from personal contacts of the committee members, who in turn proposed new candidates from their professional environment [28]. Following this process, 506 professionals were invited, of which 497 experts from all autonomous communities in Spain agreed to participate. All of them were practitioner clinical doctors: $58.4 \%$ primary care physicians; $13.7 \%$ endocrinologists; $13.9 \%$ internal medicine; $7.0 \%$ cardiologists; and $7.0 \%$ nephrologists.

\subsection{Analysis and Interpretation of Results}

A single type of rating scale was proposed for all questions, an ordinal Likert scale of nine points, from 1: total disagreement (strongly disagree/never/not important/not necessary/not at all appropriate) to 9: total agreement (strongly agree/always/very important/absolutely necessary/totally appropriate), according to the format developed at UCLARand Corporation for the evaluation method of the appropriate use of medical technology [27]. The categories were divided into three regions (1-3: Disagree; 4-6: Neutral; 7-9: Agree), systematising the submission of responses as shown in Fig. 1.

All questions had to be answered in wave 1 . In wave 2, the questions for which consensus was not achieved in wave 1 were asked again.

Consensus was deemed to be reached when a question obtained at least $80 \%$ of responses grouped in scores 1-3 (consensus in disagreement) or scores 7-9 (consensus in agreement).

Data were analysed globally and according to the by specialty of the participating doctors. The comparative analysis by specialty was conducted using the Chi-square or Fisher statistical tests. To conduct the comparative analysis between waves, Bowker's test was used, an adaptation of McNemar's test to compare variables from

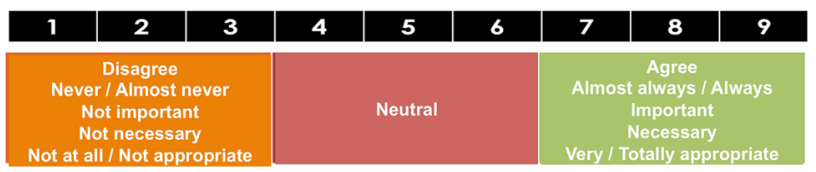

Fig. 1 Scoring scale and levels of agreement and disagreement 
more than 2 categories. In both cases the established level of statistical significance was 0.05 bilateral.

\section{Results}

The first results refer to the degree of agreement or consensus among the experts consulted about the diabetogenic effect of different statins, in the case that a patient with impaired glucose metabolism requires treatment with a statin. The consensus percentages reached (greater than $80 \%$ between respondents was considered relevant) are summarized in Table 1 and Fig. 2. Furthermore, the existing differences are shown, where applicable, between primary care physicians and those from other specialties.

The experts primarily agreed that the diabetogenic profile varies among statins. In addition, $78.9 \%$ of the specialists practically unanimously disagree with the statement that pitavastatin impairs glucose metabolism or increases the risk of onset of diabetes, being considered the safest statin in this respect.

However, there are many aspects for which agreement or a significant consensus was not reached. For example, consistent with the above, only $10.7 \%$ of the physicians believe that all statins can alter glucose metabolism. However, there are other aspects for which a greater degree of consensus was expected, for example, "the more potent statins and statins at higher doses may impair glucose metabolism or glycaemic control". Although most of the experts consider that atorvastatin, simvastatin and rosuvastatin have the greatest effect, less than $80 \%$ (considered significant) of them agree with this statement. It should be noted that primary care physicians believe that the most potent statins can impair glucose metabolism or impair its control in diabetics in a significantly higher percentage than other specialists.
The results of the second objective, concerning selection criteria of a statin in patients with abnormal glucose metabolism, and what can be considered the statin of choice are shown in Table 2 and Fig. 3. The degree of consensus in these aspects is very high. Thus, it should be noted that the recommendations for selecting a particular statin for a patient with abnormal glucose metabolism or overt diabetes mellitus are: (a) to assess the cardiovascular risk and risk of diabetes mellitus; (b) to assess the patient profile, including age, polypharmacy, kidney function and albuminuria, and levels of fasting plasma glucose and HbAlc; and (c) to select a statin that has demonstrated a neutral or beneficial effect. Regarding the statin considered the safest in the opinion of the experts consulted, the majority considers that pitavastatin is the best choice for pre-diabetic and diabetic patients (Fig. 3). It is the only statin that reaches such a consensus, being the proportion of doctors from the specialities higher (significant) in comparison with primary care physicians.

\section{Discussion}

The diabetogenicity of statins appears to be associated with the statin itself: higher lipid-lowering potency, higher doses and longer treatment duration are predisposing conditions. Patient-specific factors, such as older age, impaired kidney function, cardiovascular risk and multiple illnesses or comorbidity, which usually includes polypharmacy [29], are also key factors. Furthermore, situations considered pre-diabetic are also predisposing factors, such as patients with metabolic syndrome, visceral obesity, impaired fasting glucose or intolerance to oral glucose load $[18,19]$.

With regard to the potential different effect of the different statins, several studies have shown such differences. We found that $83.3 \%$ of doctors agree that statins have differences in their diabetogenic effect, while $78.7 \%$ of

Table 1 Degree of consensus on issues concerning the effect of statins on glucose metabolism (significant agreements and differences are indicated)

\begin{tabular}{llr}
\hline Issue $^{(1)}$ & $\begin{array}{l}\text { Degree of consensus \% } \\
(95 \% \text { CI })^{(2)}\end{array}$ & $p$ (PC vs OS) $)^{(3)}$ \\
\hline The diabetogenic profile of statins differs among them & $\mathbf{8 3 . 3}(\mathbf{8 0 . 0 - 8 6 . 6})$ & $0.0603(82.1$ vs 85.0$)$ \\
There are statins that do not impair glucose metabolism & $78.7(75.1-82.3)$ & $0.3668(77.2$ vs 80.7$)$ \\
The diabetogenic effect of statins is proven & $54.3(49.9-58.7)$ & $0.1831(52.1$ vs 57.5$)$ \\
The most potent statins may alter glucose metabolism & $52.5(48.1-56.9)$ & $<\mathbf{0 . 0 0 0 1}(\mathbf{4 4 . 8}$ vs $\mathbf{6 6 . 3})$ \\
The most potent statins may impair glycaemic control in patients with diabetes mellitus & $43.3(38.9-47.7)$ & $<\mathbf{0 . 0 0 0 1}(\mathbf{3 9 . 7}$ vs 48.3) \\
All statins at high doses may alter glucose metabolism in patients with pre-diabetes & $20.7(17.1-24.3)$ & $0.9369(21.0$ vs 20.3) \\
All statins at high doses may impair glycaemic control in patients with pre-diabetes & $20.5(17.0-24.0)$ & $0.6215(21.4$ vs 19.3$)$ \\
All statins alter glucose metabolism & $10.7(8.0-13.4)$ & $0.2468(12.4$ vs 8.2$)$
\end{tabular}

(1) Item for which the expert's opinion is requested ${ }^{(2)} 95 \%$ CI: $95 \%$ Confidence Interval. Consensus percentage $>7$ on the Likert scale. Bold values refer to an agreement above $80 \%$. ${ }^{(3)}$ PC: Primary Care; OS: Other Specialties. Bold values refer statistical significance 
Fig. 2 Degree of consensus on the evaluation of the diabetogenic effect of cholesterol-lowering drugs (Consensus percentage $\geq 7$ on the Likert scale. It is considered significant if it is above $80 \%$ ). (*) Primary care vs Other specialties

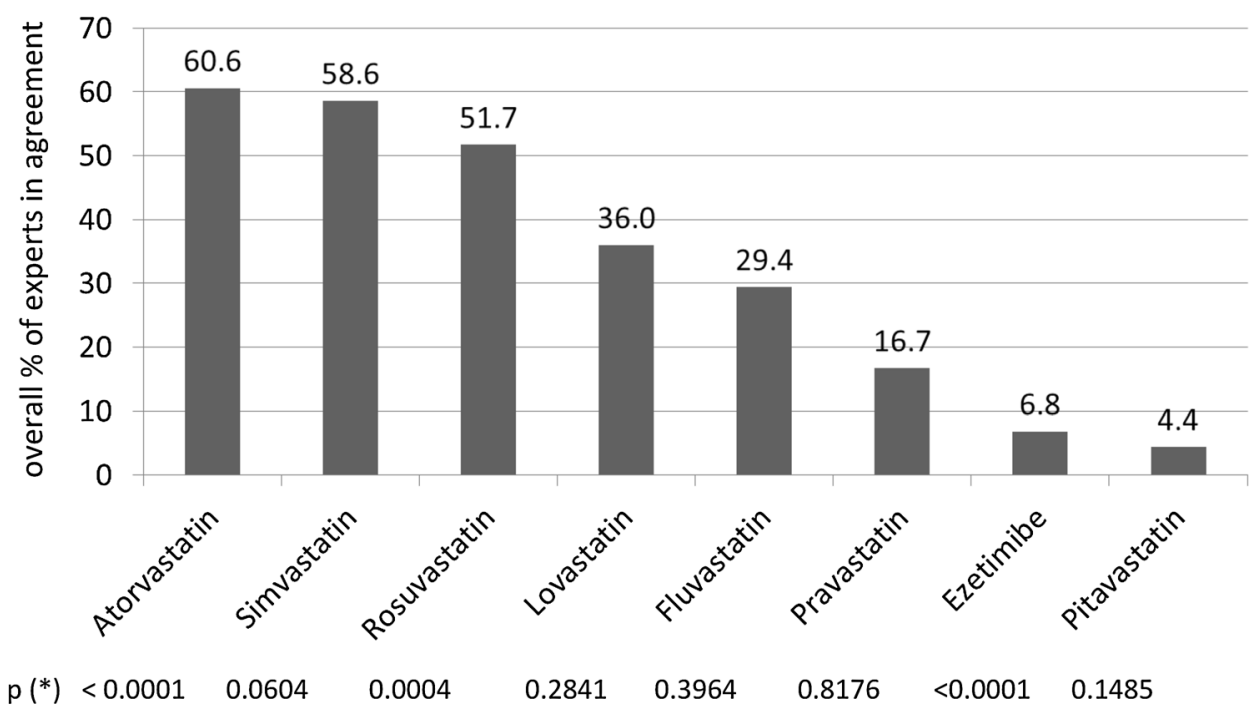

$\left({ }^{*}\right)$ Primary care vs Other specialties

Table 2 Degree of consensus on recommendations to choose a statin considering its possible effect on glucose metabolism (significant agreements and differences are indicated)

\begin{tabular}{|c|c|c|}
\hline Issue $^{(1)}$ & $\begin{array}{l}\text { Degree of consensus \% } \\
(95 \% \mathrm{CI})^{(2)}\end{array}$ & $p(\mathrm{PC} \text { vs OS })^{(3)}$ \\
\hline The cardiovascular risk must be evaluated when prescribing a statin & $94.8(92.8-96.8)$ & $0.4433(94.1$ vs 95.7$)$ \\
\hline It is useful to evaluate the patient's multiple medications when prescribing a statin & $89.5(86.8-92.2)$ & $0.5668(90.7$ vs 87.9$)$ \\
\hline It is useful to consider the patient's renal function / albuminuria when prescribing a statin & $86.5(83.5-89.5)$ & $0.4652(87.0$ vs 93.1$)$ \\
\hline $\begin{array}{l}\text { For a patient with altered glucose metabolism, a statin that has demonstrated that it does not } \\
\text { impair this metabolism should be selected. }\end{array}$ & $85.7(82.6-88.8)$ & 0.0845 (88.6 vs 81.6$)$ \\
\hline $\begin{array}{l}\text { For a diabetic patient, a statin that has demonstrated that it does not impair glucose } \\
\text { metabolism should be selected. }\end{array}$ & $84.7(81.5-87.9)$ & $0.0003(90.0$ vs 77.3$)$ \\
\hline $\begin{array}{l}\text { In the follow-up of patients in treatment with statins, glucose levels should be regularly } \\
\text { monitored. }\end{array}$ & $84.7(81.5-87.9)$ & $0.0795(83.1$ vs 87.0$)$ \\
\hline It is useful to evaluate the patient's age when prescribing a statin & $82.9(79.6-86.2)$ & $0.2053(83.8$ vs 81.6$)$ \\
\hline It is useful to consider the patient's fasting plasma glucose when prescribing a statin & $81.5(78.1-84.9)$ & $0.5370(80.3$ vs 83.1$)$ \\
\hline The risk of diabetes mellitus should be determined when prescribing a statin & $81.3(77.9-84.7)$ & $0.0150(85.2$ vs 75.8$)$ \\
\hline It is useful to consider the patient's HbA1c levels when prescribing a statin & $80.3(76.8-83.8)$ & $0.0682(77.2$ vs 84.5$)$ \\
\hline
\end{tabular}

(1) Item for which the expert's opinion is requested. ${ }^{(2)} 95 \%$ CI: $95 \%$ Confidence Interval. Consensus percentage $\geq 7$ on the Likert scale. Bold values refer to an agreement above $80 \%$. (3) PC: Primary Care; OS: Other Specialties. Bold values refer statistical significance

doctors also thought that some statins do not impair glucose metabolism, and $78.9 \%$ profoundly disagreed that pitavastatin modifies glucose metabolism. However, high doses of statins have not been identified as a key element. As a consequence, our results lead us to suspect a certain lack of awareness of the diabetogenic profile of the different statins, supported by the doubts expressed about the evidence and extent of the diabetogenic effect based on the potency of the statin, both in subjects with and without diabetes mellitus. It is worth highlighting that no differences were seen in the answers given by primary care physicians and those of other specialities.
There was consensus that pitavastatin is the best choice both in pre-diabetic patients (91.1\% consensus) and in patients who have already been diagnosed of diabetes (92.2\% consensus); while the other statins are either not considered to be a suitable choice or their suitability is unknown. There is a small but significant difference between the consensus percentages concerning the choice of pitavastatin in pre-diabetic patients when primary care physicians (91.8\% consensus) are compared to other specialists ( $90.7 \%$ consensus). This is consistent with the recent publication of the first meta-analysis focusing on the individualised effects of pitavastatin [30], which has 
Fig. 3 Degree of consensus on the statin of choice in patients with pre-diabetes or overt diabetes (Consensus percentage $\geq 7$ on the Likert scale. It is considered significant if it is above $80 \%$ ). (*) $p$ Primary care vs Other specialties

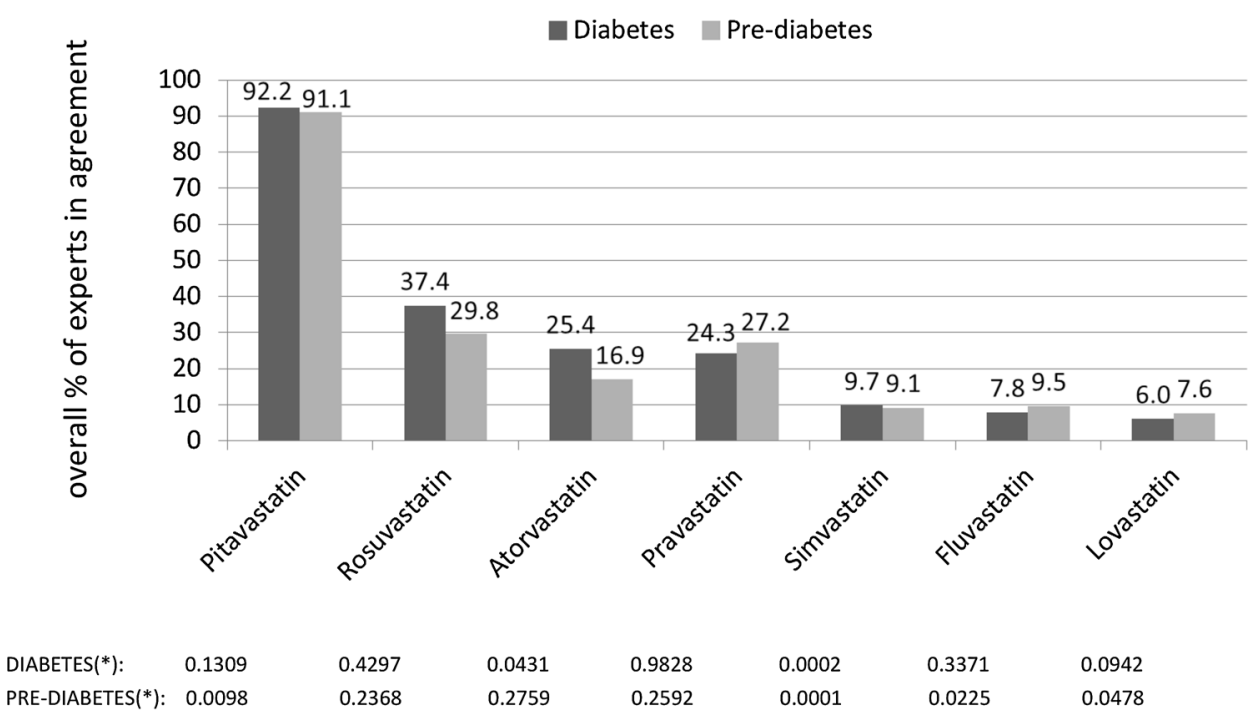

$(*)$ p Primary care vs Other specialties revealed that, relative to the controls (placebo and other statins), in subjects without prior diabetes the incidence of diabetes or deterioration of glucose metabolic control (fasting plasma glucose and/or HbAlc) is not increased. This evidence is in line with data collected in patients with impaired glucose tolerance, in these patients, pitavastatin showed a neutral effect and even some protection to the onset of diabetes [31, 32]. Summarizing, pitavastatin is perceived as the best choice, both in diabetic [29] and in pre-diabetic [33] patients.

It seems interesting to note the level of consensus concerning other recommendations when prescribing a statin. There is consensus on assessing the cardiovascular risk (94.8 \% of experts), the patient's polypharmacy ( $89.5 \%$ ) and taking into account kidney function and the presence of albuminuria $(86.5 \%)$. Likewise, $82.9 \%$ agree on the importance of considering the patient's age. It is important to mention that doctors agreed that, before prescribing a statin, it is necessary to assess the risk of developing diabetes ( $81.3 \%$ of responders), and it is necessary to select a statin that has demonstrated that it does not impair the glycaemic profile, both in diabetic patients $(84.7 \%)$ and in those with impaired glucose metabolism (85.7 \%), also, it is necessary to assess the levels of fasting plasma glucose $(84.7 \%)$ or the HbA1c levels $(80.3 \%)$.

It should be noted that primary care physicians seemed generally more concerned about the possible diabetogenic effect of statins than other specialists. They showed greater consensus on the need to monitor that the statin does not impair glycaemic control in diabetic patients $(90$ vs $77.3 \%$ ), and calculate the risk of developing diabetes mellitus prior to the use of a statin $(85.2$ vs $75.8 \%)$. This latter recommendation from our experts is aligned with the latest recommendations from experts who support assessing the risk of developing DM2 in patients who start a treatment with statins [34]. The European Atherosclerosis Society has established some recommendations to evaluate the risk of diabetes at 10 years using a validated instrument (FINDRISC), and to assess and periodically monitor the levels of fasting plasma glucose and HbAlc. This is in line with the opinion and consensus given in our study as evaluating the risk at 10 years and periodically assess the levels of plasma glucose and HbA1c is the recommendation that achieves the greatest degree of consensus among the experts consulted [34].

The selection of the statin (drug and doses) to treat high risk patients is a critical decision. Clinical benefits of pitavastatin, with focus on patients with diabetes or at risk of developing diabetes was recently published [35]. According to drug evaluation, pitavastatin is a moderate- to high-intensity statin that effectively reduces LDL cholesterol levels. In addition, provides a neutral or positive effect on glucose metabolism and does not increase the risk of new-onset diabetes. Therefore, it seems that pitavastatin should preferentially be considered in the treatment of dyslipidaemia in diabetic patients or at risk of developing diabetes. Several mechanism have been proposed to explain the association of statins and new-onset diabetes: calcium channel blockage in beta cells, decreased glucose transporter 4 (GLUT4) expression, diminished levels of coenzyme Q10, and cholesterol uptake in pancreatic beta cells [36]. These biomolecular mechanisims are the most relevant to explain the divergences but we have limited high-quality evidences to confirm the mechanism behind the different agents.

We need additional and well-designed studies to elucidate possible causes and comprehensive studies will determine potential differences among individual statins. 
The present consensus was highly significant concerning aspects such us the varying diabetogenicity of different statins, as some of them do not significantly worsen glucose metabolism. Nonetheless, more studies are needed to better understand this association as ours is only a positional study of the physician's opinion. Our study could be a contribution for a future clinical guide to support clinical decisions.

\section{Conclusions}

Finally, it should be noted that, regardless of their cholesterol-lowering power, statins should be selected based on other effects, including: (1) their effect on decreased triglycerides and increased HDL (residual vascular risk); (2) patient characteristics: age, calculated cardiovascular risk, multiple illnesses/comorbidity, multiple medications and risk of interactions, kidney function; and (3) underlying impaired glucose metabolism and potential diabetogenicity, that show differences between certain agents.

Acknowledgements The authors acknowledge the panellists participating as experts in the Delphi survey and Adelphi Spain (Barcelona), the company responsible for implementing the project, for assisting the scientific committee in project design, statistical analysis and obtaining the final results.

\section{Compliance with Ethical Standards}

Funding Laboratorios del Dr. Esteve, S.A.U. has supported the scientific committee to undertake the fieldwork of the Delphi survey for this study, without participating in the design, data analysis or drafting of this article

Conflicts of Interest Jesús Millán Núñez-Cortés, Aleix Cases Amenós, Juan Francisco Ascaso Gimilio, Vivencio Barrios Alonso, Vicente Pascual Fuster, Juan Carles Pedro-Botet Montoya, Xavier Pintó Sala and Adalberto Serrano Cumplido declare that they have no conflict of interest that might be relevant to the contents of this manuscript.

Open Access This article is distributed under the terms of the Creative Commons Attribution-NonCommercial 4.0 International License (http://creativecommons.org/licenses/by-nc/4.0/), which permits any noncommercial use, distribution, and reproduction in any medium, provided you give appropriate credit to the original author(s) and the source, provide a link to the Creative Commons license, and indicate if changes were made.

\section{References}

1. Cholesterol Treatment Trialists' (CTT) Collaboration, Baigent C, Blackwell L, Emberson J, Holland LE, Reith C, Bhala N, et al. Efficacy and safety of more intensive lowering of LDL cholesterol: a meta-analysis of data from 170,000 participants in 26 randomised trials. Lancet. 2010;376:1670-81.
2. Cholesterol Treatment Trialists' (CTT) Collaboration, Fulcher J, O'Connell R, Voysey M, Emberson J, Blackwell L, Mihaylova B, et al. Efficacy and safety of LDL-lowering therapy among men and women: meta-analysis of individual data from 174,000 participants in 27 randomised trials. Lancet. 2015;385:1397-405.

3. Shepherd J, Barter P, Carmena R, Deedwania P, Fruchart J, Haffner S, et al. Effect of lowering LDL cholesterol substancially below currently recommended levels in patients with coronary heart disease and diabetes: The Treating to New Targets (TNT) study. Diabetes Care. 2006;29:1220-6.

4. Haffner SM, Alexander CM, Cook TJ, Boccuzzi SJ, Musliner TA, Pedersen TR, et al. Reduced coronary events in simvastatintreated patients with coronary heart disease and diabetes or impaired fasting glucose levels: subgroup analyses in the Scandinavian Simvastatin Survival Study. Arch Intern Med. 1999;159:2661-7.

5. Goldberg RB, Mellies MJ, Sacks FM, Moye LA, Howard BV, Howard WJ, et al. The Care Investigators: Cardiovascular events and their reduction with pravastatin in diabetic and glucose-intolerant myocardial infarction survivors with average cholesterol levels: subgroup analyses in the cholesterol and recurrent events (CARE) trial. Circulation. 1998;98:2513-9.

6. Keech A, Colquhoun D, Best J, Kirby A, Simes RJ, Hunt D, et al. Secondary prevention of cardiovascular events with long-term pravastatin in patients with diabetes or impaired fasting glucose: results from the LIPID trial. Diabetes Care. 2003;26(10):2713-21.

7. Collins R, Armitage J, Parish S, Sleigh P, Peto R. MRC/BHF Heart Protection Study of cholesterol-lowering with simvastatin in 5963 people with diabetes: a randomised placebo-controlled trial. Lancet. 2003;361:2005-16.

8. Sever PS, Dahlof B, Poulter NR, Wedel H, Beevers G, Caulfield $\mathrm{M}$, et al. Prevention of coronary and stroke events with atorvastatin in hypertensive patients who have average or lower-thanaverage cholesterol concentrations, in the Anglo-Scandinavian Cardiac Outcomes Trial-Lipid Lowering Arm (ASCOT-LLA): a multicentre randomised controlled trial. Lancet. 2003;361:1149-58.

9. Colhoun HM, Betteridge DJ, Durrington PN, Hitman GA, Neil HA, Livingstone SJ, et al. Primary prevention of cardiovascular disease with atorvastatin in type 2 diabetes in the Collaborative Atorvastatin Diabetes Study (CARDS): multicentre randomised placebo-controlled trial. Lancet. 2004;364:685-96.

10. Golomb BA, Evans MA. Statin adverse effects: a review of the literature and evidence for a mitochondrial mechanism. Am J Cardiovasc Drugs. 2008;8:373-418.

11. Pinto X, Formiga F. Las estatinas, el riesgo de diabetes y el tratamiento de la hipercolesterolemia en la población anciana. Rev Esp Geriatr Gerontol. 2012;47:245-6.

12. Sattar N, Taskinen MR. Statins are diabetogenic. Myth or reality? Atheroscler Suppl. 2012;13:1-20.

13. Swerdlow DI, Sattar N. A dysglycaemic effect of statins in diabetes: relevance to clinical practice? Diabetologia. 2014;57:2433-5.

14. DuBroff RJ. The statin diabetes conundrum: short-term gain, long-term risk or inconvenient truth? Evid Based Med. 2015;20:121.

15. Macedo AF, Douglas I, Smeeth L, Forbes H, Ebrahim S. Statins and the risk of type 2 diabetes mellitus: cohort study using de UK clinical practice research datalink. BMC Cardiovasc Disord. 2014;14:85.

16. Rajpathak SN, Kumbhani DJ, Crandall J, Barzilai N, Alderman M, Ridker PM. Statin therapy and risk of developing type 2 diabetes: a meta-analysis. Diabetes Care. 2009;32:1924-9.

17. Sattar N, Preiss D, Murray HM, Welsh P, Buckley BM, de Craen $\mathrm{AJ}$, et al. Statins and risk of incident diabetes: a collaborative 
meta-analysis of randomised statin trials. Lancet. 2010;375:735-42.

18. Ridker PM, Pradhan A, Mac Fadyen JG, Libby P, Glynn RJ. Cardiovascular benefits and diabetes risks of statin therapy in primary prevention: an analysis from the JUPITER trial. Lancet. 2012;380:565-71.

19. Water DD, Ho JE, Demicco DA, Breazna A, Arsenault BJ, Wun $\mathrm{CC}$ et al. Predictors of new-onset diabetes in patients treated with atorvastatin: results from 3 large randomized clinical trials. J Am Coll Cardiol. 2011; 57: 1535-45.

20. Preiss D, Seshasai SR, Welsh P, Murphy SA, Ho JE, Waters DD, et al. Risk of incident diabetes with intensive-dose compared with moderate-dose statin therapy: a metaanalysis. JAMA. 2011;305:2556-64.

21. Carter AA, Gomes T, Camacho X, Juurlink DN, Shah BR, Mamdani MM. Risk of incident diabetes among patient treated with statins: population based study. BMJ. 2013;346:2610.

22. Dormuth CR, Filion KB, Paterson JM, James MT, Teare GF, Raymond CB, et al. Higher potency statins and the risk of new diabetes: multicenter, observational study of administrative databases. BMJ. 2014;348:g3244.

23. Dalkey NC. The Delphi method: an experimental study of group opinion. Santa Monica: Rand Corporation; 1969.

24. Dalkey NC, Brown B, Cochran S. The Delphi method, III: use of self ratings to improve group estimates. Santa Monica: Rand Corporation; 1969.

25. Fick DM, Cooper JW, Wade WE, Waller JL, Maclean JR, Beers $\mathrm{MH}$. Updating the Beers criteria for potentially inappropriate medication use in older adults. Results of a US consensus panel of experts. Arch Intern Med. 2003;163:2716-24.

26. Peiro S, Portella E; El grupo nominal en el entorno sanitario. Quaderns de Salut Publica i Administració de Serveis de Salut 1. Valencia: Escola Valenciana d'Estudis per a la Salut; 2003.

27. Royle P, Waugh N. Literature searching for clinical and costeffectiveness studies used in health technology assessment reports carried out for the National Institute for Clinical Excellence appraisal system. Health Technol Assess. 2003;7:1-51.
28. Goodman LA. Snowball sampling. Ann Math Stat. 1961;32:148-70.

29. Rius J, Millán J, Pedro-Botet J, Pintó X. La diabetogenicidad de las estatinas: ¿son todas iguales? Estado de la cuestión. Clin Invest Arterioscler. 2015;27:148-58.

30. Vallejo-Vaz AJ, Kondapally SR, Kurogi KM, Michishita I, Nozue T, Sugiyama S, et al. Effect of pitavastatin on glucose, $\mathrm{HbA1c}$ and incident diabetes: a meta-analysis of randomized controlled clinical trials in individuals without diabetes. Atherosclerosis. 2015;241(2):409-18.

31. Navarese EP, Buffon A, Andreotti F, Kozinski M, Welton N, Fabiszak T, et al. Meta-analysis of impact of different types and doses of statins on new-onset diabetes mellitus. Am J Cardiol. 2013;111:1123-30.

32. Culver AL, Ockene IS, Balasubramanian R, Olendzki BC, Sepavich DM, Wactawski-Wende J, et al. Statin use and risk of diabetes mellitus in postmenopausal women in the Women's Health Initiative. Arch Intern Med. 2012;172:144-52.

33. Teramoto $\mathrm{T}$, Urashima $\mathrm{M}$, Shimano $\mathrm{H}$, Yokote $\mathrm{K}$, Saito $\mathrm{Y}$, LIVES Study Extension Group. A Large-Scale Survey on CardioCerebrovascular Events During Pitavastatin (LIVALO Tablet) Therapy in Japanese Patients with HypercholesterolemiaLIVALO Effectiveness and Safety Study Extension (LIVES Study Extension). Jpn Pharmacol Ther. 2011;39:789-803.

34. Sattar NA, Ginsberg H, Ray K, Chapman MJ, Arca M, Averna M, et al. The use of statins in people at risk of developing diabetes mellitus: evidence and guidance for clinical practice. Atheroscler Suppl. 2014;15:1-15.

35. Barrios V, Escobar C. Clinical benefits of pitavastatin: focus on patient with diabetes or at risk of developing diabetes. Future Cardiol. 2016. doi:10.2217/fca-2016-0018.

36. Backes JM, Kostoff MD, Gibson CA, Ruisinger JF. Statin-associated diabetes mellitus: review and clinical guide. South Med J. 2016;109:167-73. 